\title{
Successful Behavioral Interventions, International Comparisons, and a Wonderful Variety of Topics for Clinical Practice
}

\author{
Marjorie A. Bowman, MD, MPA, and Anne Victoria Neale, PhD, MPH
}

This is the issue of successful behavioral interventions and international comparisons that support the need for better primary health care in the United States. Men's preconception care is considered, and the issue rounds out with articles about the radiologic findings of fluid in the mastoid bone, sex of physicians and mortality rates, a diabetes drug review, and, as usual, some informative brief case reports. (J Am Board Fam Med 2013;26:105-107.)

\section{Behavioral Interventions-With Success!}

A successful obesity intervention! We have a very important article-one with amazing outcomes: improvement in obesity among children that persisted for a year resulted from a group visit intervention at a family medicine residency that included the parents and the children (third through fifth grades), both separately and together. ${ }^{1}$ The intervention was based on positive psychology and resiliency. This intervention seems feasible, so please repeat it and study the outcomes!

Dickinson et $\mathrm{al}^{2}$ report a computer-based interactive behavior change intervention that positively assisted patients with health behavior change. They also note difficulties with patient recruitment and suggest that the intervention might work better if it was integrated into the interaction between primary care clinicians and patients, rather than as a separate intervention. Then, just as if it was ordered up (perhaps by all hopeful clinicians and patients), Goodyear-Smith et $\mathrm{al}^{3}$ report an innovation in New Zealand called eChat. This programmatic innovation provides an electronically completed set of questionnaires before a family physician visit, with the results available for use during the visit. eChat reviews a variety of behavioral and preventive topics, provides self-help, as well as prioritization and request for assistance from the physicians. This has great potential to assist both physicians and patients toward the goal of improving patient engagement and tar-

Conflict of interest: The authors are editors of the $7 A B F M$. geted interventions, and we look forward to reports on the overall outcomes.

In another helpful report, Strayer et $\mathrm{al}^{4}$ created a handheld personal digital assistant software program that incorporates the major methods recommended to enhance smoking cessation by patients. A group of residents and attending physicians used it, on average, just more than once per month (ie, not with most of their smokers). They reported that use of eChat increased their reported comfort with and use of specific techniques, which are the first steps toward adoption by physicians.

So how to get these changes to happen in practice? Part IV of Maintenance of Certification (MOC) is related to improving quality and practice. Part IV portion of the MOC process has proven far more successful than many would have predicted, including myself (MAB). This MOC requirement has led to a tremendous amount of quality improvement (QI) work within groups and across practices as well as new thinking about how to improve quality and practices. Fisher et $\mathrm{al}^{5}$ report process and outcomes with group QI projects within a large, regional, family medicine MOC collaboration; their findings are instructive and provide optimism for ongoing improvement.

\section{The Message from Cross- International Comparisons: More Primary Health Care Teams!}

Neggers and Crowe ${ }^{6}$ take on an international comparison of the rate of low birth weight. Smoking 
and anemia are higher in Cuba, yet low birth weight is significantly lower than in the United States (particularly Alabama) and is decreasing. What gives? The authors visited Cuba and provide information about some major differences in prenatal care, with a heavy dose of responsibility for family physicians, which might be an important explanation for the cross-national differences. Ventres ${ }^{7}$ also has visited south of the border, particularly to Cuba and El Salvador, and notes the increasing emphasis on primary health care, frequently with the use of physician, nurse, and community health workers. Both of these articles provide interesting examples from international perspectives on how far behind the United States is in providing team primary care.

In a further emphasis on prevention, Warner and Frey ${ }^{8}$ provide a review of preconception health care for men. While a preconception visit is widely viewed as important for women, the importance for men often has been overlooked.

\section{Wonderful Variety (or Wonderful Family Doc Miscellany)}

Many physicians look at new drugs with cynicism, appropriately so, because of previously distressing experiences with increased costs without increased benefit. Painter et al, ${ }^{9}$ who report no conflicting interest, review one of the newer medications, an extended release version of exenatide (to be taken once a week). The authors' review of the data indicates that there are some advantages for this long-acting over the previous shorter-acting version of the drug at similar cost, and they provide other information about its use.

The Canadian Hypertension Education Program has a list of 13 recommendations on how to measure blood pressure. While many family physicians report they regularly adhere to the recommendations, there are several that they did not believe were important or else the time-consuming nature did not seem worth it. Furthermore, we challenge you: do you truly follow every one of these recommendations for every patient for whom you are measuring blood pressure? We suspect very few blood pressure readings happen to follow all recommendations. In addition, do we truly know how much difference each of these recommendations make in the diagnosis, treatment, and outcomes of high blood pressure?

There is some literature suggesting differences in the practice styles of male and female physician providers. The question is, "Is the sex of the physician associated with differential patient outcomes, including the ultimate outcome-death?" Read Jerant et $\mathrm{al}^{10}$ to see what these authors found by analyzing a national database.

Just look at the photograph of a red, intertriginous rash that appears in the Wilmer and Hatch ${ }^{11}$ detailed case report; what would be your diagnosis? The authors discuss the diagnosis of this rash, which had been understandably misdiagnosed. Consider the hints next time you see a rash similar to this one.

Fluid in mastoid cells can be seen on various radiology studies, including magnetic resonance imaging, computed tomography, or radiographs. In fact, as $\mathrm{McDonald}$ et $\mathrm{al}^{12}$ note, this can be seen in many patients with otitis media. The authors clearly review the key issue: When is it serious and urgent?

Van dijk et $\mathrm{al}^{13}$ review the megatrials of bronchodilators in chronic obstructive pulmonary disease and note the lack of evidence for improved outcomes, particularly death.

Primary care researchers are eager to use electronic medical record (EMR) databases to identify patients with chronic conditions. Kadhim-Saleh et $\mathrm{al}^{14}$ provide a methods article to explore the quality of data and the validity of diagnostic algorithms for 5 chronic diagnoses. They conducted a retrospective validation study of EMR-based diagnostic algorithms, comparing the concordance of data from a primary abstraction of patients' EMRs within the Canadian Primary Care Sentinel Surveillance Network national database. The diabetes algorithm had excellent test characteristics and provides confidence that this would be a reliable method for identifying patients with diabetes.

Xierali et al ${ }^{15}$ report that family physicians provide a lot of mental health care-even more so in rural areas, where there are so few psychiatrists. Family physicians will do whatever they can to help their patients, including stretching their knowledge to their patients' needs in rural America.

\section{Communities of Solution Theme Issue}

In May we will publish our special theme issue focused on articles that take a "community of solution" approach to improving care. We had a wonderful response to our call for papers, and this upcoming issue will include excellent, innovative articles. 


\section{References}

1. Siwik V, Kutob R, Ritenbaugh C, et al. Intervention in overweight children improves body mass index (BMI) and physical activity. J Am Board Fam Med 2013;26:126-137.

2. Dickinson WP, Glasgow RE, Fisher L, et al. Use of a website to accomplish health behavior change: if you build it, will they come? And will it work if they do? J Am Board Fam Med 2013;26:168-176.

3. Goodyear-Smith F, Warren J, Elley CR. The eCHAT program to facilitate healthy changes in New Zealand primary care. J Am Board Fam Med 2013;26:177-182.

4. Strayer SM, Heim SW, Rollins LK, et al. Improving smoking cessation counseling using a point-of-care health intervention tool: from the Virginia Practice Support and Research Network (VaPSRN). J Am Board Fam Med 2013;26:116-125.

5. Fisher DM, Brenner CJ, Cheren M, Stange KC. Engagement of groups in family medicine board maintenance of certification. J Am Board Fam Med 2013;26:149-158.

6. Neggers Y, Crowe K. Low birth weight outcomes: why better in Cuba than Alabama? J Am Board Fam Med 2013;26:187-195.

7. Ventres WB. The emergence of primary care in Latin America: reflections from the field. J Am Board Fam Med 2013;26:183-186.

8. Warner JN, Frey KA. The well-man visit: addressing a man's health to optimize pregnancy outcomes. J Am Board Fam Med 2013;26:196-202.

9. Painter NA, Morello CM, Singh RF, McBane SE. An evidence-based and practical approach to using Bydureon $^{\mathrm{TM}}$ in patients with type 2 diabetes. J Am Board Fam Med 2013;26:203-210.

10. Jerant A, Bertakis KD, Fenton JJ, Franks P. Sex of physician as the usual source of care and patient health care utilization and mortality. J Am Board Fam Med 2013;26:138-148.

11. Wilmer EN, Hatch RL. Resistant "candidal intertrigo": could inverse psoriasis be the true culprit? J Am Board Fam Med 2013;26:211-214.

12. McDonald MH, Hoffman MR, Gentry LR. When is fluid in the mastoid cells a worrisome finding? J Am Board Fam Med 2013;26:218-220.

13. van Dijk WD, van den Bemt L, van Weel C. Megatrials for bronchodilators in chronic obstructive pulmonary disease (COPD) treatment: time to reflect. J Am Board Fam Med 2013;26:221-224.

14. Kadhim-Saleh A, Green M, Williamson T, Hunter D, Birtwhistle R. Validation of the diagnostic algorithms for 5 chronic conditions in the Canadian Primary Care Sentinel Surveillance Network (CPCSSN): a Kingston practice-based research network (PBRN) report. J Am Board Fam Med 2013;26:159-167.

15. Xierali IM, Tong ST, Petterson SM, Puffer JC, Phillips RL, Bazemore AW. Family physicians are essential for mental health care delivery. J Am Board Fam Med 2013;26:114-115. 